\title{
Método de extração de sílica da casca do arroz
}

\section{(Method of extration of silica from rice hull)}

\author{
L. Fernandes, M. G. Sabino, H. L. Rossetto \\ Inovamat - Inovação em Materiais Ltda., R. Nestor de Campos 986, S. Carlos, SP, Brasil 13562-101 \\ hebert@inovamat.com.br
}

\begin{abstract}
Resumo
A influência dos ácidos cítrico, acético e oxálico na extração da sílica a partir da casca do arroz foi estudada. As condições experimentais da extração, como pressão e concentração ácida, também foram estudadas. De acordo com o tamanho dos poros pela adsorção de $\mathrm{N}_{2}$, conforme método BET, foram classificadas como mesoporosa. Comparações entre diferentes tipos de ácidos utilizados foram realizadas pela área de superfície específica da sílica obtida.O ácido que apresentou melhor desempenho foi o acético, resultando em área de superfície específica $271 \mathrm{~m}^{2} / \mathrm{g}$; o ácido cítrico apresentou o melhor resultado de pureza, 99,96\%.

Palavras-chave: palha de arroz, sílica, mesoporoso, área de superfície específica.
\end{abstract}

\begin{abstract}
In this work the influence of citric, acetic and oxalic acids on the extraction of nanometric silica from rice hull was studied. The experimental conditions of extraction, such as pressure and acid concentration, were also studied. According to the pore size evaluated by $N_{2}$ adsorption (BET method), the specimens were classified as mesoporous. Comparisons between different types of acids used were performed by evaluation of the specific surface area of the silica obtained. Acetic acid showed the best performance, resulting in silica with a specific surface area of $271 \mathrm{~m}^{2} / \mathrm{g}$. Citric acid showed the best result in terms of purity, $99.96 \%$.
\end{abstract}

Keywords: rice hull, silica,mesoporous,specific surface area.

\section{INTRODUÇÃO}

O objetivo da extração de sílica $\left(\mathrm{SiO}_{2}\right)$ de elevada pureza a partir da casca do arroz (CA) é obter um material com potencial para diversas aplicações tecnológicas. Aplicações em materiais inorgânicos, com ênfase em vidros, refratários, tubos cerâmicos e abrasivos se mostram consolidadas, contudo inovações têm surgido. Trabalhos recentes relatam a extração de sílica da casca do arroz, que em conjunto com acetato de alumínio, gera mulita [1]. Uma área promissora para aplicação de sílica mesoporosa é a Medicina [2], à qual estudos recentes mostram a eficácia da sílica como carreador de fármacos para o tratamento de tumores cerebrais e tópicos. Áreas emergentes de aplicação de sílica ocorrem para adição à borracha, o que inclui pneus ecológicos, síntese de sílica gel, xerogel a partir de resíduos de bagaço [3], xerogel com uso de ácido acético como catalisador [4], nanogel e materiais nano-estruturados, entre outros.

O Brasil produz atualmente cerca de 12,7 milhões de toneladas de arroz, estando entre os 10 maiores produtores do mundo. Considerando que a casca representa cerca de $3 \%$ da massa da planta do arroz e que a casca pode acumular até $15 \%$ em massa de sílica, sendo assim,cerca de 57.000 toneladas de sílica poderiam estar disponíveis ao consumo pelo mercado pressupondo que beneficiadores de arroz brasileiros adotassem tecnologia adequada para as 381.000 toneladas de casca geradas anualmente no país. A título de ilustração, esse montante permitiria ao país dobrar sua produção anual de sílica, introduzindo produtos mais sofisticados ao mercado e ao mesmo tempo, reduzindo o volume de importações que afetam de modo significativo à balança comercial brasileira.

Algumas aplicações da sílica extraída da casca do arroz seriam estratégicas a setores pujantes da economia brasileira, tais como: (i) agricultura, como matéria prima para a fabricação de silicatos de potássio; (ii) indústria de higiene pessoal e cosméticos, demandante de sílica com alta pureza, que muito se beneficiaria com a disponibilidade de produtos sofisticados e com apelo sustentável; (iii) indústria de bebidas, que se beneficiaria de uma sílica com elevada pureza e área superficial específica graças ao papel que a sílica desempenha, por exemplo, na clarificação de compostos indesejáveis à cerveja; (iv) indústria sucroalcooleira, para a qual a sílica pode ser utilizada na obtenção de peneiras moleculares em colunas separadoras capazes de transformar o álcool etílico hidratado (96\%) em álcool etílico anidro $(99,6 \%)$ que é adicionado à gasolina; e (v) indústria farmacêutica, como excipiente e também matéria prima para obtenção de sílica gel.

Presentemente, a sílica da casca do arroz que tem sido extraída pelas empresas em operação no país, resulta geralmente com baixa pureza e área superficial específica, consequentemente de baixo valor agregado. Um desses mercados é o de concreto de alto desempenho, para o qual, ainda assim, se torna atraente em função da sua natureza amorfa, ao contrário da sílica quartzosa mineral, 
e da sua relativa pureza quando comparada à sílica que resulta como subproduto da produção de ferro-silício. Vários processos técnicos mostraram rotas para a extração da sílica; a fundamental estratégia usada é a lavagem da casca com soluções ácidas, com esta operação é possível solubilizar grande parte dos elementos sódio, potássio, ferro, manganês, cálcio, e alumínio. Um processo técnico [5] usou o ácido clorídrico $(\mathrm{HCl})$ para a lavagem da casca. Nesta tecnologia, soluções a $20 \%$ (vol/vol) foram usadas. Um método mostrou que o ácido clorídrico pode ser usado em concentração menor da ordem de $10 \%$ (vol/vol), obtendo pureza relativa de até $99,44 \%$ [6]; o ácido nítrico também foi empregado em trabalhos acadêmicos [6], em concentrações elevadas é demonstrado a solubilização de grande parte da matéria orgânica $(74 \% \mathrm{~m} / \mathrm{m})$ após $12 \mathrm{~h}$ de tratamento sobre aquecimento $\left(70{ }^{\circ} \mathrm{C}\right)$, outros agentes oxidantes foram utilizados como o ácido sulfúrico [9]; contudo, tais métodos necessitam de equipamentos em nível industrial vitrificados devido ao alto poder oxidante destes ácidos, o que inviabiliza a técnica de extração de sílica de alta pureza e elevada área superficial específica da casca do arroz, além de oferecem riscos operacionais, que devem ser controlados com nível máximo de segurança operacional o que também encarece o processo industrial. Neste trabalho diferentemente aos expostos foram propostos a utilização de três ácidos fracos (ácido cítrico, ácido acético e ácido oxálico) para a etapa de lavagem da casca do arroz [8], que comprovadamente demonstra que o processamento da casca de arroz é decisivo para que a sílica seja extraída de modo a preservar a riqueza de poros interconectados que a natureza propícia ao acomodá-la em contato íntimo com as fibras de celulose na parede celular da casca do arroz; tal escolha destes ácidos também se justifica pelo fato de não haver a necessidade de revestimentos vítreos na autoclave e com reduzidos riscos operacionais.

Neste trabalho estudou-se a influência dos ácidos cítrico, acético e oxálico na extração da sílica a partir da casca do arroz, mantendo-se fixas as demais variáveis do processamento. Os resultados são discutidos em termos de pureza e, principalmente, área superficial específica da sílica obtida.

\section{PROCEDIMENTO EXPERIMENTAL}

As matérias primas utilizadas neste estudo foram: casca do arroz natural do Rio Grande do Sul (Indústria Alibaba Alimentos, Itu, SP), ácido acético PA (J. T. Baker), ácido cítrico anidro (grau técnico) e ácido oxálico PA (Synth).

A obtenção de sílica a partir de casca de arroz ocorreu pela lavagem em meio ácido, em soluções a 10\% (massa/ massa) de ácidos acético, cítrico e oxálico. A casca de arroz é lavada, com o intuito de solubilizar as impurezas detrimentais à qualidade da sílica nela contida. A lavagem se dá em autoclave (Phoenix Luferco AV 100) com relação entre massa de casca e solução ácida constante de 1:9 (massa:massa), pressão constante de $1,5 \mathrm{kgf} / \mathrm{cm}^{2}$ e tempo de permanência na autoclave de $1 \mathrm{~h}$. Posteriormente, a casca é seca em estufa (Quimis Q317M) para subsequente calcinação em forno tipo mufla (Quimis Q318M) e moagem em moinho de bolas. Para a obtenção de uma amostra de referência, denominada S0, pesou-se $60,0 \mathrm{~g}$ de casca do arroz (CA) previamente seca em estufa. Em seguida, a casca foi diretamente calcinada a $700{ }^{\circ} \mathrm{C}$ por $2 \mathrm{~h}$, suficiente para remover a matéria orgânica e resultar em dióxido de silício (sílica), além de outros óxidos em menor teor, tais como os de ferro, magnésio, manganês, sódio e potássio. Para a obtençãodas amostras S1, S2 e S3, soluções para a lavagem da casca foram preparadas mantendo a razão entre casca/solução de 1/9 (massa/massa); a sequência de ácidos utilizados foi o ácido cítrico, ácido acético e ácido oxálico, respectivamente. As suspensões foram levadas isoladamente para uma autoclave onde permaneceram por $1 \mathrm{~h}$ a $127^{\circ} \mathrm{C} \pm 5$ ${ }^{\circ} \mathrm{C}$. Em seguida, as cascas foram lavadas com água corrente até a total neutralização, sendo a última lavagem com água destilada. A umidade da casca foi retirada em estufa a 100 ${ }^{\circ} \mathrm{C} \pm 5{ }^{\circ} \mathrm{C}$ durante $12 \mathrm{~h}$, sendo na seqüência calcinada para remoção da matéria orgânica em forno mufla entre $600 \mathrm{e}$ $700{ }^{\circ} \mathrm{C}$ por $2 \mathrm{~h}$. A última etapa foi a moagem em moinho de bolas por $21 \mathrm{~h}$ para atingir a granulometria micrométrica, com a relação em peso de 10 partes de bolas de zircônia para 1 parte de sílica. Para a obtenção da amostra S4, manteve-se a razão em massa de casca/solução de 1/9, e a solução usada foi o ácido cítrico $10 \%$ (massa/massa). Da mesma forma, a suspensão permaneceu em autoclave por $1 \mathrm{~h}$ a $127^{\circ} \mathrm{C}$. Em seguida, a casca foi lavada repetidas vezes com água potável até a neutralização da suspensão, tendo a última lavagem sido realizada com água destilada. Depois, retirou a umidade da casca em estufa a $100{ }^{\circ} \mathrm{C} \pm 5^{\circ} \mathrm{C}$ por $12 \mathrm{~h}$. Essa casca, dita pré-tratada, foi submetida a uma segunda lavagem ácida com solução de ácido cítrico a $10 \%(\mathrm{~m} / \mathrm{m})$, mantendo a relação sólido/líquido em 1:9 em massa e o mesmo ciclo de $1 \mathrm{~h}$ em autoclave a $127{ }^{\circ} \mathrm{C} \pm 5{ }^{\circ} \mathrm{C}$. Em seguida, a casca foi lavada com água corrente até a neutralização (última lavagem com água destilada) e seca em estufa à $100^{\circ} \mathrm{C} \pm 5{ }^{\circ} \mathrm{C}$ por $1 \mathrm{~h}$. Uma terceira e última lavagem foi feita nos moldes das duas anteriores. Essa casca foi então calcinada em forno mufla a $600{ }^{\circ} \mathrm{C}$ por $2 \mathrm{~h}$; a massa obtida foi submetida a moagem em moinho de bolas por $21 \mathrm{~h}$ em meio líquido (álcool isopropílico) com um dispersante (poliacrilato de amônio).

Todas as amostras de sílica obtidas foram caracterizadas via técnicas de ICP-MS (Plasma Indutivamente Acoplado a Espectrômetro de Massa) em equipamento ThermoXseriesII, energia dispersiva de raios $X$ (EDS), fluorescência de raios X (FRX), área de superfície específica (ASE) pelo método BET em equipamento Quantachrome Autosorb e microscopia eletrônica de varredura (MEV-FEG), em equipamento Philips XL-30 FEG.

\section{RESULTADOS E DISCUSSÃO}

Para extrair a sílica da casca de arroz com elevado nível de pureza é necessário primeiramente realizar a lavagem ácida da casca. Este estudo utilizou os ácidos cítrico anidro, acético glacial e oxálico, a partir dos quais 
Tabela I - Composição química das amostras de sílica.

[Table I - Chemical composition of the silica samples.]

\begin{tabular}{|c|c|c|c|c|c|c|c|c|}
\hline \multirow[b]{2}{*}{ Amostra } & \multicolumn{8}{|c|}{ Composição química (\% massa) } \\
\hline & $\begin{array}{l}\text { Silício } \\
\left(\mathrm{SiO}_{2}\right)\end{array}$ & $\begin{array}{c}\text { Potássio } \\
\left(\mathrm{K}_{2} \mathrm{O}\right)\end{array}$ & $\begin{array}{c}\text { Sódio } \\
\left(\mathrm{Na}_{2} \mathrm{O}\right)\end{array}$ & $\begin{array}{c}\text { Manganês } \\
(\mathrm{MnO})\end{array}$ & $\begin{array}{l}\text { Cálcio } \\
(\mathrm{CaO})\end{array}$ & $\begin{array}{c}\text { Ferro } \\
\left(\mathrm{Fe}_{2} \mathrm{O}_{3}\right)\end{array}$ & $\begin{array}{c}\text { Alumínio } \\
\left(\mathrm{Al}_{2} \mathrm{O}_{3}\right)\end{array}$ & $\begin{array}{c}\text { Fósforo } \\
\left(\mathrm{P}_{2} \mathrm{O}_{5}\right)\end{array}$ \\
\hline S0 & 96,5 & 1,37 & 0,08 & 0,17 & 0,56 & 0,07 & 0,13 & 0,42 \\
\hline S1 & 99,8 & 0,12 & $\mathrm{Nd}$ & nd & nd & nd & nd & nd \\
\hline S2 & 99,6 & 0,08 & 0,09 & 0,06 & 0,06 & nd & nd & 0,14 \\
\hline S3 & 99,7 & 0,04 & $\mathrm{Nd}$ & 0,01 & 0,03 & 0,02 & 0,08 & 0,09 \\
\hline S4 & 99,96 & 0,0044 & 0,0061 & 0,0024 & 0,0099 & 0,0040 & 0,0127 & nd \\
\hline
\end{tabular}

nd: não detectado

foi possível alcançar uma pureza sempre superior a $99,6 \%$ e área superficial específica superior a $180 \mathrm{~m}^{2} / \mathrm{g}$. As demais variáveis do processamento permaneceram constantes para comparação do efeito de cada ácido sobre a pureza e área superficial específica. De acordo com a Tabela I, a sílica extraída da casca de arroz sem tratamento ácido (amostra S0) apresentou cerca de 3,5\% em massa de impureza composta pelos elementos potássio, sódio, manganês, cálcio, ferro e alumínio. A lavagem da casca com solução a $10 \%$ em massa de ácido oxálico permitiu reduzir tais impurezas a um teor de $0,3 \%$ em massa, além do aumento da área superficial específica de $72 \mathrm{~m}^{2} / \mathrm{g}$ para $180 \mathrm{~m}^{2} / \mathrm{g}$, este último valor sendo ainda o menor em relação ao dos demais ácidos deste estudo. A Tabela II permite concluir sobre o efeito de cada ácido sobre os parâmetros de interesse da sílica, isto é, pureza e área superficial específica.

Em geral, observa-se que todos os ácidos foram eficientes quanto à remoção dos íons inorgânicos (cálcio, sódio, potássio, alumínio, ferro e magnésio), os quais, além da pureza, teriam papel importante na formação de fase vítrea com a sílica durante a etapa de calcinação, com conseqüência sobre a área superficial específica. Esse é o motivo da área superficial específica de amostras que passaram por lavagem ácida apresentar valor cerca de três vezes superior à amostra referência. A lavagem com ácido acético (amostra S2) foi a que possibilitou extrair a sílica da casca de arroz com a maior área superficial específica: $271 \mathrm{~m}^{2} / \mathrm{g}$, e com a pior

Tabela II - Tamanho de poro, área superficial específica e pureza das amostras de sílica.

[Table II - Pore size, specific surface area and purity of the samples of silica.]

\begin{tabular}{cccc}
\hline Amostra & $\begin{array}{c}\text { Pureza } \\
\left(\% \mathrm{SiO}_{2}\right)\end{array}$ & $\begin{array}{c}\text { Tamanho } \\
\text { de poro } \\
(\mathrm{nm})\end{array}$ & $\begin{array}{c}\text { Área Superficial } \\
\text { Específica } \\
\left(\mathrm{m}^{2} / \mathrm{g}\right)\end{array}$ \\
\hline S0 & $96,5(* *)$ & 8,4 & 72 \\
S1 & $99,8(*)$ & 4,4 & 235 \\
S2 & $99,6(*)$ & 4,4 & 271 \\
S3 & $99,7(* *)$ & 4,4 & 180 \\
S4 & $99,96(* * *)$ & 4,8 & 224 \\
\hline
\end{tabular}

*EDS; **FRX; ***ICP-MS.
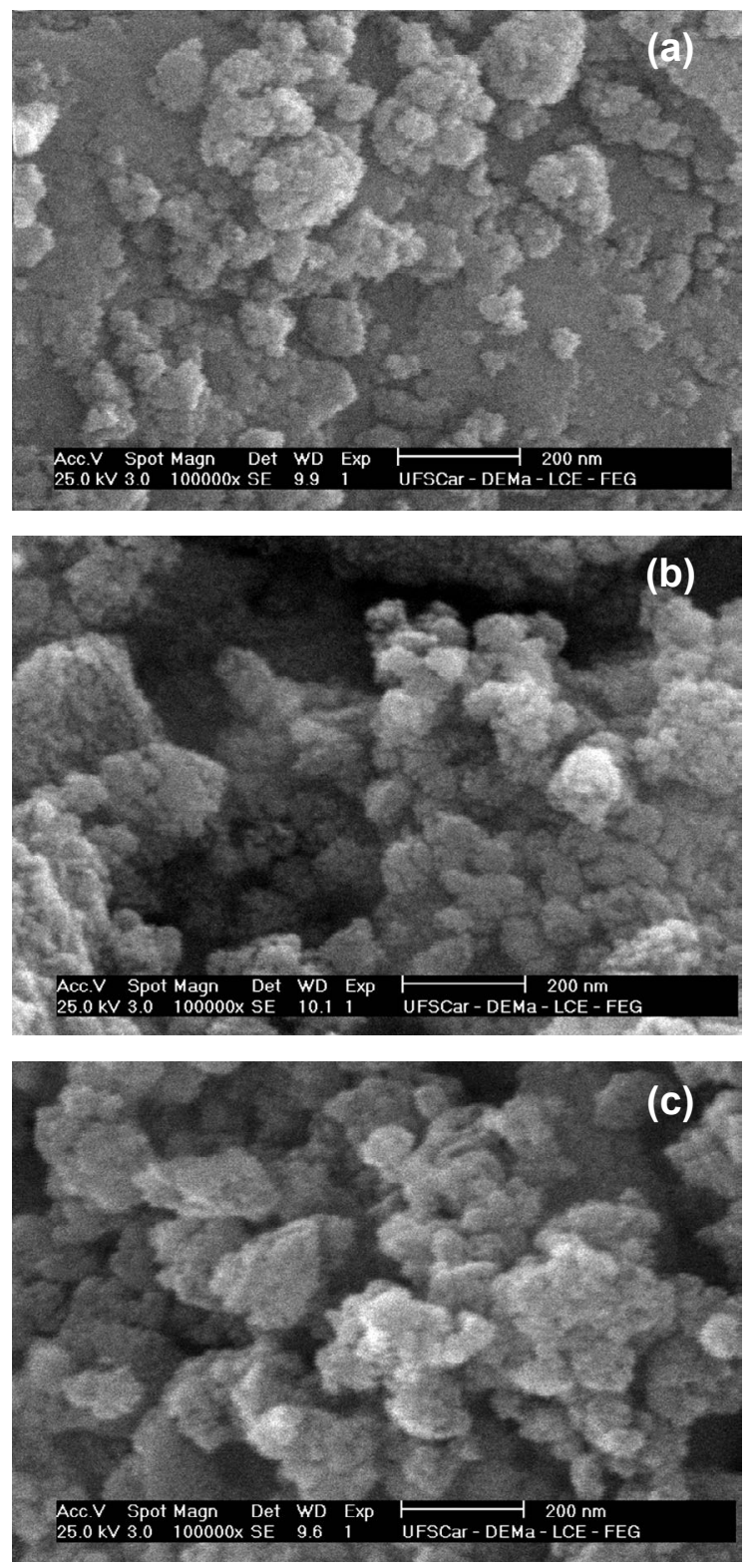

Figura 1: Micrografias obtidas por microscopia eletrônica de varredura das amostras de sílica obtidas com diferentes ácidos: a) ácido cítrico $10 \%$; b) ácido acético $10 \%$ e c) ácido oxálico $10 \%$. [Figure 1: SEM micrographs of samples of silica obtained with different acids: a) citric acid 10\%; b) acetic acid 10\% and c) oxalic acid $10 \%$.] 
pureza relativa de 99,6\%. Já a lavagem com o ácido cítrico (amostra S1) permitiu extrair sílica da casca de arroz com a maior pureza, 99,8\%. A extensão da lavagem da casca do arroz com ácido cítrico por três ciclos (amostra S4) permitiu obter uma pureza maior, 99,96\%, como mostra a Tabela II, praticamente sem prejuízo à área superficial específica.

As amostras também foram caracterizadas quanto à morfologia e, conforme a Fig. 1, apresentam aspectos muito próximos de estrutura morfológica com pequenos aglomerados de partículas primárias com dimensões entre 50 e 60 nm, visualizados nas ampliações das Figs. 1c e 1d. Porém, não se pode inferir que os diferentes ácidos usados na lavagem da casca de arroz influenciaram a morfologia das partículas de sílica.

De acordo com a classificação do tamanho dos poros, Tabela II, pode-se inferir que a características das partículas no caso de serem microporosas o poro deve ser menor que $2 \mathrm{~nm}$; para mesoporosos a faixa compreendida está entre 2 e $50 \mathrm{~nm}$ e para macroporosos os poros devem ser maiores que $50 \mathrm{~nm}$ [10]. No caso das amostras extraídas da casca do arroz S1 $(4,4 \mathrm{~nm}), \mathrm{S} 2(4,4 \mathrm{~nm}), \mathrm{S} 3(4,4 \mathrm{~nm})$ e S4 $(4,8 \mathrm{~nm})$, inclusive a amostra referência $\mathrm{S} 0(8,4 \mathrm{~nm})$, todas possuem a faixa de porosidade para materiais mesoporosos.

\section{CONCLUSÕES}

A partir de um processamento inovador foi possível extrair sílica da casca de arroz na forma com partículas de 100 a $200 \mathrm{~nm}$, formadas por aglomerados de partículas ainda menores, entre 50 e $60 \mathrm{~nm}$, com elevadas pureza e área superficial específica. Um dos diferenciais desse processamento é a etapa de lavagem ácida da casca de arroz, em autoclave, antes de sua calcinação. Diferentes ácidos proporcionaram diferentes valores para os parâmetros de interesse da sílica, isto é, pureza e área superficial específica. A lavagem com ácido cítrico resultou na sílica com a maior pureza: $99,9 \%$ para um ciclo e $99,96 \%$ para três ciclos de lavagem. A lavagem com ácido acético, por sua vez, resultou em sílica com pureza ligeiramente inferior, $99,6 \%$, porém, com a maior área superficial específica alcançada neste estudo, $271 \mathrm{~m}^{2} / \mathrm{g}$. A sílica assim obtida é classificada como mesoporosa, segundo a avaliação por adsorção de nitrogênio, o que lhe confere uma miríade de aplicações tecnológicas com elevado valor agregado para algumas das indústrias mais pujantes da economia nacional.

\section{REFERÊNCIAS}

[1] R. R. Menezes, E. Fagury-Neto, M. C. Fernandes, P. M. Souto, R. H. G. A. Kiminami, Cerâmica 54, 330 (2008) 245252.

[2]F. Tang, L. Li, D. Chen, "Mesoporous Silica Nanoparticles: Synthesis, Biocompatibility and Drug Delivery", Adv. Mater. 24 (2012) 1504-1534.

[3] S. Affandi, H. Setyaman, S. Winardi, R. Balgis, Adv. Powder Techn. 20 (2009) 468-472.

[4] L. Arenas, C. W. Simm, Y. Gushikem, S. L. P. Dias, C. C. Moro, T. M. H. Costa, E. V. Benvenutti, J. Braz. Chem. Soc, 18, 5 (2007) 886-890.

[5] M. F. Tonon, T. T. Gomes, I. S. Silva, INPI PI $0805412-$ 6 A2 $(24 / 12 / 2008)$.

[6] I. A. Rahman, J. Ismail, H. Osman, J. Mater. Chem. 7, 8 (1997) 1505-1509.

[7] C. Real, M. D. Alcala, J. M. Criado, J. Am. Ceram. Soc. 79, 8 (1996) 2012-16.

[8] L. Fernandes, D. C. Moreira, H. L. Rossetto, INPI PI $221010929750(20 / 12 / 2010)$.

[9] C. R. da Cunha, J. S. Júnior, F. L. S. de Carvalho, U. P. R. Filho, P. R. Oliveira, M. A. S. Silva, Química Nova 33, 4 (2010) 794-797.

[10] M. N. Rahaman, Ceramic Processing and Sintering, $2^{\text {nd }}$ Ed., Marcel Dekker Inc., New York, EUA (2003) 150.

(Rec. 23/01/2013, Rev. 04/04/2013, Ac. 15/11/2013) 